\title{
Factors predisposing to a complicated initial febrile convulsion
}

\author{
SHEILA J. WALLACE \\ From the Department of Child Life and Health, University of Edinburgh
}

\begin{abstract}
Wallace, S. J. (1975). Archives of Disease in Childhood, 50, 943. Factors predisposing to a complicated initial febrile convulsion. 131 consecutive admissions to hospital for a first febrile convulsion were studied to find which factors predisposed to a complicated fit-defined as one lasting more than 30 minutes, unilateral, or repeated within the same illness. A significant excess of complicated attacks occurred where the age of onset was less than 16 months, where both family history of convulsive disorder and perinatal abnormality were present, and, in females only, where it was suspected that neurological disorder preceded the first fit.
\end{abstract}

A febrile convulsion is defined here as any convulsion occurring in association with any febrile illness. It is further defined as complicated if it continues for more than half an hour, has unilateral features, or is repeated within the same illness. Such convulsions increase the likelihood of further febrile seizures, persisting neurological disorder, suboptimal mental development, and generalized or temporal lobe epilepsy (Aicardi and Chevrie, 1970; Bamberger and Matthes, 1959; Degen and Goller, 1967; Doose et al., 1966; Falconer, Serafetinides, and Corsellis, 1964; Gastaut et al., 1960; Horstmann and Schinnerling, 1963; Hrbek, 1957; Lennox-Buchtal, 1973; Ounsted, Lindsay, and Norman, 1966; Schmidt, 1958; Wallace, 1974). It seems relevant to search for the causes of a complicated convulsion.

The present study compares 81 children whose initial convulsive episode was complicated, with 50 in whom there was a single generalized initial fit lasting less than half an hour. All 131 were seen at the Royal Hospital for Sick Children, Edinburgh.

\section{Patients and methods}

The 131 children were sequential admissions to hospital for febrile convulsions in whom family history, perinatal details, and developmental history were complete. All were aged more than 3 months and less than 7 years at the time of their first fit, and were febrile or had evidence of active infection. The temperature recorded as near the time of the fit as possible was noted.

Received 10 April 1975.
A careful history of the convulsive episode was taken. Particular note was taken of the presence of unilateral clonic movements, even if the fit later became generalized, the duration of the tonic/clonic stage, and the number of separate tonic/clonic attacks. Only if a single completely generalized convulsion lasting less than half an hour had been present is it defined as simple. All other convulsions are classed as complicated.

The patients were divided into two groups. (a) Complicated fit; 50 males, 31 females, total of 81 . (b) Simple fit, 32 males, 18 females, total of 50.

Histories of convulsive disorder in parents and sibs were sought. Note was made of which children had those perinatal problems found significantly more often in the same group of patients than in their sibs (Wallace, 1972). A detailed developmental history was taken and neurological examination performed. Neurological disorder before the first fit was suspected in those children who had favoured the limbs of one side early in either reaching or walking, showed unchanging abnormal neurological signs throughout their illness and followup, had dwarfing of the limbs on one side in association with a hemiplegia, or whose motor milestones were more than 2 SDs above the mean for age given by Neligan and Prudham (1969). No child was more than mildly affected, nor had any received previous medical attention for neurological symptoms or signs. Viral studies were available in 53 patients. Serum sodium levels were obtained within 6 hours of the fit in 120 children. Sibs who had not themselves had fits were examined neurologically (82 patients) and by electroencephalograph (EEG) (70 patients).

The children were categorized according to sex, family history of convulsive disorder, the presence of at least one significant perinatal problem and prior neurological disorder. In subsequent analysis, correction was made for these factors. The influences of the 943 
TABLE I

Distribution of children with each type of fit

\begin{tabular}{|c|c|c|c|c|c|c|}
\hline \multirow{4}{*}{ Sex } & \multicolumn{6}{|c|}{ Type of fit } \\
\hline & \multirow{3}{*}{ Simple } & \multicolumn{5}{|c|}{ Complicated } \\
\hline & & \multicolumn{2}{|c|}{ Generalized } & \multicolumn{3}{|c|}{ With focal features } \\
\hline & & $\begin{array}{c}\text { Duration } \\
\geqslant \frac{1}{2}\end{array}$ & $\begin{array}{c}\text { Repeated } \\
\text { within same } \\
\text { illness }\end{array}$ & $\begin{array}{c}\text { Duration } \\
<\frac{1}{2} h\end{array}$ & $\begin{array}{c}\text { Duration } \\
\geqslant \frac{1}{2} h\end{array}$ & $\begin{array}{l}\text { Repeated } \\
\text { within same } \\
\text { illness }\end{array}$ \\
\hline $\begin{array}{l}\text { Male } \\
\text { Female }\end{array}$ & $\begin{array}{l}32 \\
18\end{array}$ & $\begin{array}{r}11 \\
5\end{array}$ & $\begin{array}{l}15 \\
12\end{array}$ & $\begin{array}{l}5 \\
6\end{array}$ & $\begin{array}{l}9 \\
5\end{array}$ & $\begin{array}{r}10 \\
3\end{array}$ \\
\hline
\end{tabular}

following on the type of initial convulsive episode were examined: age at onset, viral infection, neurological abnormality in at least one sib, and EEG abnormality in at least one sib. The influence of previous feverish illness, temperature of at least $38.9^{\circ} \mathrm{C}$, and serum sodium $<130 \mathrm{mEq} / \mathrm{l}$ within 6 hours of the fit were examined after further correction for age at onset.

After summation of observed values for each factor in each category of patient, expected values were calculated and summed and the differences submitted to the $x^{2}$ test of significance.

\section{Results}

Eighty-one of the 131 patients $(62 \%)$ had an initial attack which was multiple, had unilateral features, or lasted more than 30 minutes. The number of children having each type of fit is shown in Table I. Where differences between children with complicated and simple fits occurred, the trend was the same for each type of complicated fit. The findings for all complicated fits are therefore presented together (Table II).

Neither males nor females showed a greater propensity to a complicated initial convulsion $\left(x^{2}=0 \cdot 07, \mathrm{NS}\right)$. A nonsignificant excess of males with a positive family history of convulsions had a simple initial fit $\left(\chi^{2}=2 \cdot 09, \mathrm{NS}\right)$. When considered singly, a positive history for convulsions in parents and/or sibs or a perinatal abnormality were not enough in either sex significantly to increase the risk, but if both were present a significant excess of children had a complicated initial fit $\left(x^{2}=4 \cdot 72\right.$, $P<0 \cdot 05)$. Prior neurological disorder did not appear to influence the severity of the males' initial convulsions $\left(\chi^{2}=0 \cdot 297\right.$, NS), but was significantly associated with a complicated initial fit in females $\left(x^{2}=4.52, \mathrm{P}<0.05\right)$. Histograms showing the type of fit against the age of onset for males and females separately showed in both sexes, but particularly in the males, a significant tendency for children younger than 16 months to have complicated fits $\left(x^{2}=6 \cdot 34, P<0 \cdot 02\right)$ (Fig. $\left.1 \& 2\right)$. A
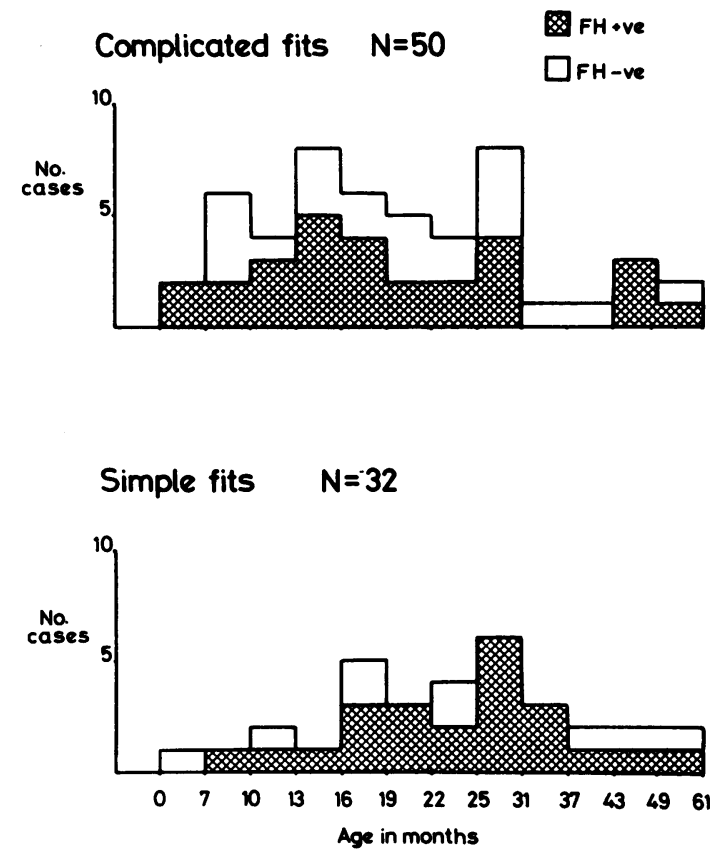

Fig. 1.-Type of fit related to age at onset in 82 males. $F H$, family history.

surprisingly high proportion (65\%) of the children had had previous feverish illnesses including measles, without having had a convulsion, and even after correction for age of onset there was no excess of children with a complicated fit among those who were thought to be suffering from their first fever $\left(x^{2}=0 \cdot 2, \mathrm{NS}\right)$. Recorded temperatures of at least $38.9{ }^{\circ} \mathrm{C}$ were not significantly related to complicated fits $\left(\chi^{2}=0.52\right.$, NS). An excess of proven viral infections was found in the children with complicated fits, but was not significant $\left(x^{2}=3 \cdot 16, \mathrm{NS}\right)$. Serum sodium levels of $<130$ $\mathrm{mEq} / \mathrm{l}$ were not particularly associated with 
TABLE II

Comparison between children with complicated and simple initial fits

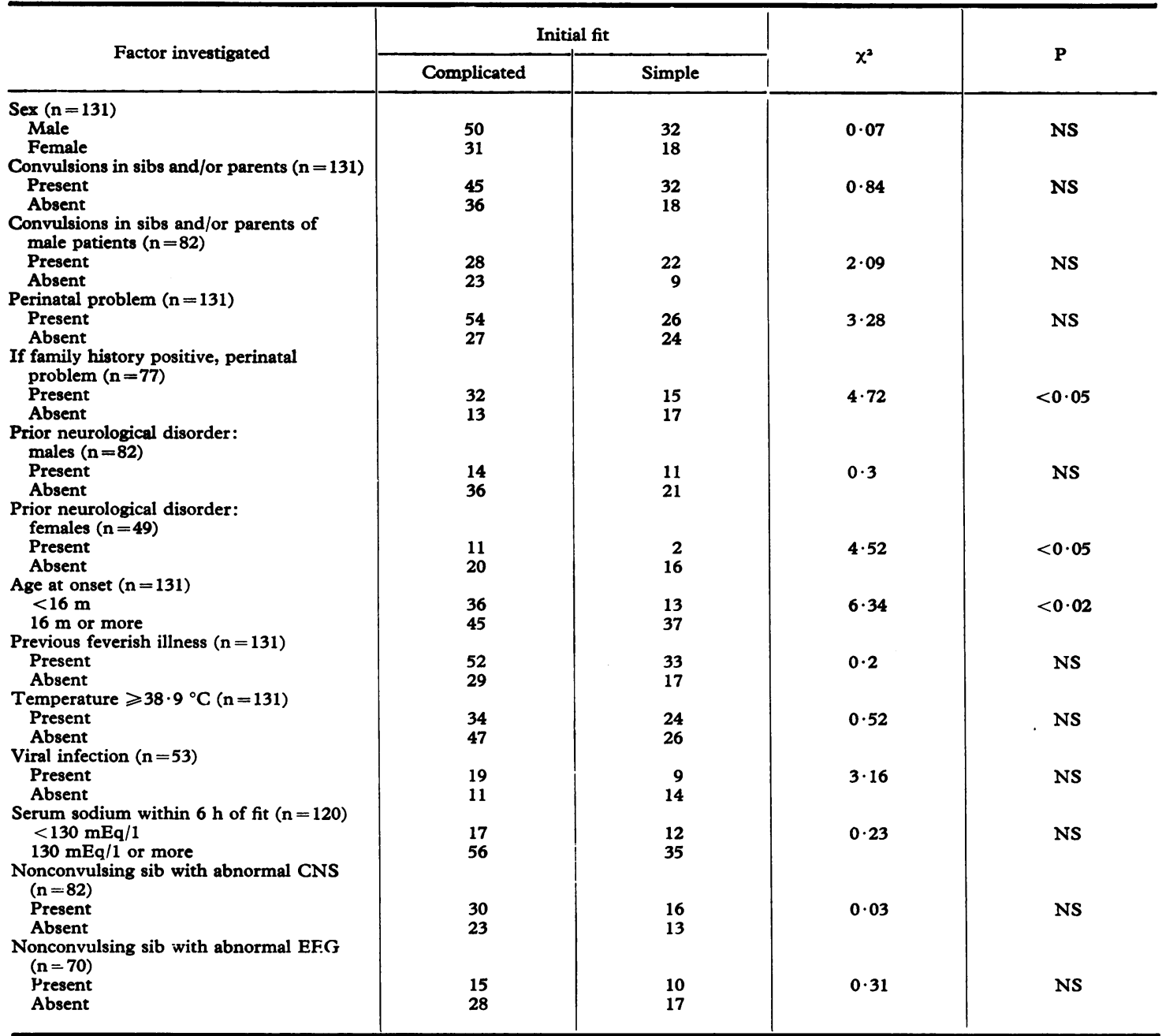

NS, not significant.

either type of fit $\left(x^{2}=0 \cdot 23\right.$, NS). Neurological abnormality in at least one nonconvulsing sib did not appear to influence whether the index case had a complicated or simple initial fit $\left(\chi^{2}=0 \cdot 03, \mathrm{NS}\right)$. Nor did EEG abnormality in at least one nonconvulsing $\mathrm{sib}\left(\chi^{2}=0 \cdot 31, \mathrm{NS}\right)$.

\section{Discussion}

The study investigates the possibility that in those children where the initial convulsive episode is prolonged, multiple, or has unilateral features, there are factors predisposing to a complicated fit.
Compared with other reports, $62 \%$ is an unusually high proportion for complicated attacks. All patients in this series were admitted to hospital, but no other selection was made. Previous incidences for multiple, unilateral, or prolonged febrile convulsions have varied from 25 to $37 \%$ (Doose et al., 1966; Herlitz, 1941 ; Lennox, 1949; LennoxBuchtal, 1973). The definition of severity is variable in these studies, making direct comparison difficult. It is also likely that full details of lateralizing features may not have been available.

The finding that neither the males nor the fe- 
Complicated fits $\quad \mathrm{N}=31$

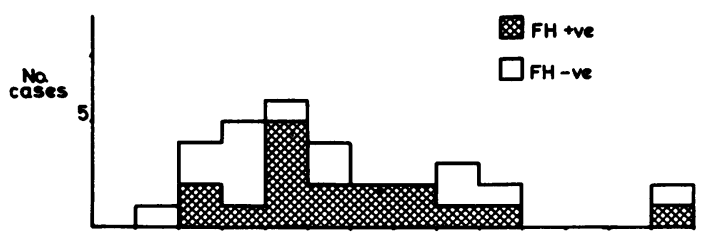

Simple fits $\quad N=18$

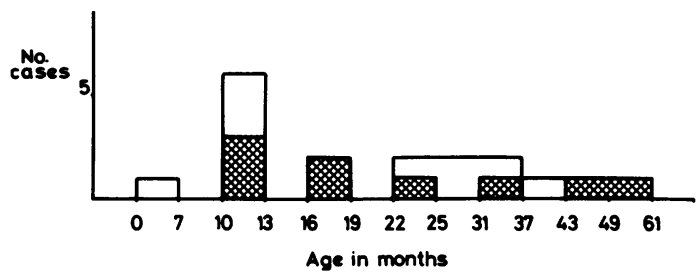

Fig. 2.-Ty'pe of fit related to age at onset in 49 females. FH, Family history.

males in this study appeared to be more prone to a complicated initial convulsion is at variance with some studies where girls seem more susceptible to prolonged or unilateral fits (Herlitz, 1941; Aicardi and Chevrie, 1970; Taylor and Ounsted, 1971). However, these findings are not strictly comparable with those of the present group since the authors did not restrict themselves to the initial convulsive episode and the larger the number of fits suffered, the more likely is a severe one to have occurred (Lennox-Buchtal, 1973). The Gentofte series also failed to show a female preponderance for prolonged or unilateral convulsions (LennoxBuchtal, 1973).

The influence of family history on the severity of individual convulsions does not appear to have been examined previously, but it has been reported that males with a negative family history are a group least likely to suffer severe sequelae (Taylor and Ounsted, 1971). The present study showed that males with a positive family history were less likely to have a complicated fit. This suggests that inheritance of the febrile convulsion trait might protect males against a fit carrying a serious prognosis. Further evidence for the absence of simple positive correlation of hereditary factors with complicated fits is found in the analysis of the sibs' neurological and EEG data.

Although the children with a significant perinatal abnormality had a higher risk of a complicated initial fit, this risk was significantly increased only where the family history was positive. It is probable that in these cases summation of two independent factors is responsible for perpetuation and/or lateralization of the convulsive process.

Prior neurological damage was associated with a complicated initial fit in the females only. Few studies of febrile convulsions report findings on neurological examination, and information which might suggest that neurological disorder existed before the convulsion is almost entirely lacking. However, Lennox-Buchtal (1973) reports personal communications which show a higher incidence of convulsions with fever in cerebral-palsied children than in the general population, but no relation to the type of fit or sex of the affected children is given. Bamberger and Matthes (1959) found that unilateral convulsions frequently arise as a result of brain damage regardless of its aetiology. It is not surprising that prior neurological disorder predisposes to prolongation or lateralization of a convulsion, but the explanation for this appearing in girls and not boys is obscure. The theory of differential cerebral maturation of Taylor and Ounsted (1971) might suggest that the effect of age and the presence of neurological disorder could combine to make those girls with abnormal symptoms and signs liable to convulse at an age at which they are prone to a complicated seizure. However, the present study did not confirm that girls more often had complicated seizures at a younger age than boys.

Although most authors agree with the present conclusion that younger children are more severely affected, the critical age below which convulsions are more likely to be complicated has varied. Lennox (1949) and Doose et al. (1966) suggest up to 12 months, the present study up to 15 months, and Aicardi and Chevrie (1970) up to 18 months. The finding that younger boys were more likely to have a complicated initial seizure contrasts with previous series where younger girls have seemed more vulnerable (Herlitz, 1941; Taylor and Ounsted, 1971).

Attention has been directed to the height and rapid rise in fever in the causation of febrile convulsions but correlation between these features and the type of fit has been infrequent. The present study, which fails to show a relation between a high fever and a complicated fit, agrees with Herlitz (1941). The finding that complicated fits occurred more often in children in whom positive evidence of viral infection was found agrees with the work of Lennox-Buchtal (1973). Evidence from studies in children who have positive viral findings suggests that their complicated fits are often symptoms of 
encephalitis, rather than mere responses to fever (Wallace and Zealley, 1970).

Although Nyhan and Cooke (1956) have reported very low serum sodium levels in association with persisting convulsive activity, and Millichap, Madsen and Aledort (1960), and Melekian, Laplane, and Debray (1962) have found levels of less than $130 \mathrm{mEq} / \mathrm{l}$ in some children with febrile convulsions, Lennox-Buchtal (1973) finds insufficient evidence that hyponatraemia causes febrile convulsions. In addition, 21 of a control series of 33 children without convulsions whose temperatures were at least $37 \cdot 8^{\circ} \mathrm{C}$ were found to have serum sodium levels of less than $130 \mathrm{mEq} / 1$ (unpublished data). It is therefore not surprising that the type of fit appeared to be uninfluenced by the serum sodium level.

In conclusion, evidence is presented that those children whose first febrile convulsion occurs before the age of 16 months, those who have both a positive family history of convulsive disorder and a perinatal insult, and those females thought to have had neurological disorder before the fit, carry a significant risk that their first febrile convulsion will last longer than 30 minutes, have unilateral features, or be repeated within the same illness. It may therefore be postulated that some of the serious sequelae of febrile convulsions are determined before or at the time the first fit starts.

\section{REFERENCES}

Aicardi, J., and Chevrie, J. J. (1970). Convulsive status epilepticus in infants and children. Epilepsia, 11, 187.

Bamberger, P., and Matthes, A. (1959). Anfälle im Kindesalter, p. 396. Karger, Basle.

Degen. R., and Goller, K. (1967). Die sogenannten Fieberkrămpfe des Kindesalters und ihre Beziehungen zur Epilepsie. Nervenarzt, 38, 55.

Doose, H., Petersen, C. E., Völzke, E., and Herzberger, E. (1966). Fieberkrampfe und Epilepsie. I. Atiologie, Klinisches Bild und Verlauf der sogenannten Infekt- oder Fieberkrämpfe. Archiv für Psychiatrie und Nervenkrankheiten, vereinigt mit Zeitschrift für die gesamte Neurology und Psychiatrie, 208, 400.

Falconer, M. A., Serafetinides, E. A., and Corsellis, J. A. N. (1964). Etiology and pathogenesis of temporal lobe epilepsy. Archives of Neurolog.y, 10, 233.

Gastaut, H., Poirier, F., Payan, H., Salamon, G., Toga, M., and Vigouroux, M. (1960). H.H.E. syndrome. Hemiconvulsions, hemiplegia, epilepsy. Epilepsia, 1, 418.
Herlitz, G. (1941). Studien uber die sogenannten Initialen Fieberkrampfe bei Kindern.. Acta Paediatrica, 29, Suppl. 1.

Horstmann, W., and Schinnerling, W. (1963). Zur Prognose der sogenannten Fieberkrampfe. Monatsschrift für Kinderheilkunde, 111, 52.

Hrbek, A. (1957). Fieberkrämpfe im Kindersalter. Annales Paediatrici, 188, 162.

Lennox, M. A. (1949). Febrile convulsions in childhood. A clinical and electroencephalographic study. American fournal of Diseases of Children, 78, 868 .

Lennox-Buchtal, M. A. (1973). Febrile Convulsions. A Reappraisal. Elsevier, Amsterdam.

Melekian, R., Laplane, R., and Debray, P. (1962). Considerations cliniques et statistiques sur les convulsions au cours des deshydrations aigues. Annales de Pédiatrie, 9, 290.

Millichap, J. G., Madsen, J. A., and Aledort, L. M. (1960). Studies in febrile seizures. V. Clinical and electroencephalographic study in unselected patients. Neurology, 10, 643.

Neligan, G. A., and Prudham, (1969). Norms for four standard developmental milestones by sex, social class, and place in family. Developmental Medicine and Child Neurology, 11, 413.

Nyhan, W. L., and Cooke, R. E. (1956). Symptomatic hyponatremia in acute infections of the central nervous system. Pediatrics, 18, 604.

Ounsted, C., Lindsay, J., and Norman, R. (1966). Biological factors in temporal lobe epilepsy. Clinics in Developmental Medicine, no. 22. Heinemann, London.

Schmidt, R. P. (1958). Sequelae of febrile convulsions. Medical Clinics of North America, 42, 389.

Taylor, D. C., and Ounsted, C. (1971). Biological mechanisms influencing the outcome of seizures in response to fever. Epilepsia, 12, 33.

Wallace, S. J. (1972). Aetiological aspects of febrile convulsions: pregnancy and perinatal factors. Archives of Disease in Childhood, 47, 171.

Wallace, S. J. (1974). Recurrence of febrile convulsions. Archives of Disease in Childhood, 49, 763.

Wallace, S. J., and Zealley, H. (1970). Neurological, electroencephalographic and virological findings in febrile children. Archives of Disease in Childhood, 45, 611.

I thank all the paediatricians at the Royal Hospital for Sick Children, Edinburgh, for allowing their patients to be studied, in particular Dr. T. T. S. Ingram for continual advice and encouragement; and the EEG recordists for their patience with a difficult age group. Serum sodium estimations were performed in the laboratory of the Department of Child Life and Health, University of Edinburgh, under Dr. T. E. Iles and Dr. N. Belton. A grant was received by S.J.W. from the fund given to the University of Edinburgh by the Distillers Company.

Correspondence to Dr. Sheila J. Wallace, Department of Child Health, University Hospital of Wales, Heath Park, Cardiff CF4 4XW. 